\title{
Scheie Syndrome
}

National Cancer Institute

\section{Source}

National Cancer Institute. Scheie Syndrome. NCI Thesaurus. Code C61265.

An autosomal recessive disorder representing the milder form of mucopolysaccharidosis type I. It is characterized by deficiency of the enzyme alpha-L-iduronidase. Signs and symptoms include broad mouth with full lips, cloudy cornea which may lead to blindness, stiff joints, and hirsutism. 